\title{
Las fortificaciones medievales en Andalucía 0ccidental. Un legado a conservar
}

\author{
Juan Clemente Rodríguez Estévez \\ Departamento de Historia del Arte. \\ Universidad de Sevilla
}

\begin{abstract}
Resumen
Breve aproximación a la problemática que plantea el conocimiento y conservación de las fortificaciones medievales de Andalucía Occidental. Considerando la herencia de la Antigüedad, se destacan los aspectos más relevantes de la arquitectura defensiva realizada por los musulmanes de Al-Andalus y la Corona castellana.
\end{abstract}

\section{Palabras clave}

Castillos y murallas/ Arquitectura medieval/ Arquitectura militar/ Fortificaciones medievales/ Fortificaciones de Al-Andalus

\section{Una aproximación al problema}

Durante la Edad Media la arquitectura militar gozó de una gran importancia en Andalucía, cuando murallas y castillos dominaban su paisaje. La presencia cotidiana de la guerra en la sociedad medieval, cobró una especial intensidad en un territorio eminentemente fronterizo, disputado por reinos y civilizaciones. Por naturaleza inestable y conflictivo, en él las fortificaciones se erigieron en la más elevada expresión de un poder que, a través de ellas defendía la integridad de sus dominios y los administraba. Pocos testimonios materiales reflejan de un modo tan fiel la vertebración de la tierra andaluza y de las propias sociedades que se asentaron en ella durante la Edad Media.

Hoy, sin embargo, las fortificaciones han visto socavada la prestancia que antaño tuvieron, cuando no su orgullosa figura. Ausentes en nuestras ciudades, por aditamentos y mutilaciones, se pierden desvalidas en la lejanía, cuando transitamos -apresuradamente- por nuestras autopistas. Su deterioro es muy superior al de otros tipos de construcciones coetáneas, lo cual, en cierta medida, se debe a su propia condición utilitaria. Concebidas, esencialmente, para repeler toda suerte de agresiones, con frecuencia, eran sometidas a un largo proceso de destrucción. Acontecimientos no muy lejanos, como la Guerra de la Independencia, acarrearon nuevas desgracias para fábricas muy antiguas y deterioradas. Sirva como ejemplo el caso del castillo de los Guzmanes en Niebla. Como tantos otros, había sido utilizado como cuartel por las tropas francesas del mariscal Soult, quien tras abandonarlo, decidió su voladura en 1812. Con frecuencia, aquellas fortalezas que mantuvieron su uso original, también se vieron amenazadas por ampliaciones y reformas, que atendían a las nuevas técnicas de defensa y a las necesidades de una vida más cómoda. Una vez perdido su valor defensivo o residencial, no sufrieron mejor suerte. Algunas recibieron usos muy inadecuados. Como ocurriera con la famosa fortaleza jiennense de Baños de la Encina, la onubense de Santa Olalla de Cala, acogió un cementerio, que debilitó notablemente sus muros. En otros casos, sencillamente, conocieron el más duro de los abandonos. La pérdida de su valor estratégico, así como el alejamiento del medio rural y la ruina económica vivida por la nobleza, a lo largo de los últimos siglos, contribuyeron a un abandono acelerado por la acción de la propia naturaleza.

Detrás de este penoso catálogo de infortunios, se halla una falta absoluta de valoración, es decir, una falta de conocimiento. Hasta hace muy poco, los muros defensivos de muchas poblaciones andaluzas, permanecían mudos, rodeados de un halo de leyenda, sólo escudriñado por impenitentes eruditos locales y por algunos historiadores y arqueólogos sensibilizados con la materia. Sin embargo, la situación, desde hace un tiempo, ha comenzado a cambiar. La recuperación material y el estudio del patrimonio militar andaluz es una meta que, planteada por particulares e instituciones públicas, se basa en un cúmulo de circunstancias:

- La nueva conciencia dominante sobre el patrimonio histórico, en general, permite un reconocimiento de estos monumentos, hasta hace muy poco tiempo negado.

- El desarrollo e impulso de la identidad de las comunidades locales, hallan en este tipo de obras un elemento simbólico de referencia; por cuanto suelen aparecer asociadas a una serie de hechos memorables, con frecuencia mitificados, tendentes a ennoblecer el propio pasado de cada población. 
- La disposición de unos inmuebles, que suelen presentar grandes espacios abiertos, una ubicación privilegiada y un entorno atractivo, permite su explotación para la realización de espectáculos y celebraciones públicas. La instalación en el siglo XVI de un corral de comedias, en el Patio de la Montería de los Alcázares de Sevilla, supuso una experiencia teatral que hoy se ha recuperado en el edificio sevillano y aplicado con gran éxito en el Castillo de Niebla. Desde el siglo XIX, algunas fortalezas convirtieron sus patios de armas en plazas de toros, tal como puede advertirse en las localidades onubenses de Aroche y Almonaster la Real. Y, en fechas más recientes, la de Cumbres Mayores, ha instalado en su interior un pintoresco campo de fútbol (foto I).

- Muy en relación con estos hechos, se halla la posibilidad de explotar los monumentos con fines económicos, atendiendo al creciente aumento del turismo cultural en la región. Desde hace cuatro décadas, la red de Paradores Nacionales de turismo abrió una vía, secundada más tarde por la iniciativa privada. Pero, en un sentido más general, el acceso organizado a los castillos y alcazabas se ha convertido en todo un reclamo para los visitantes,

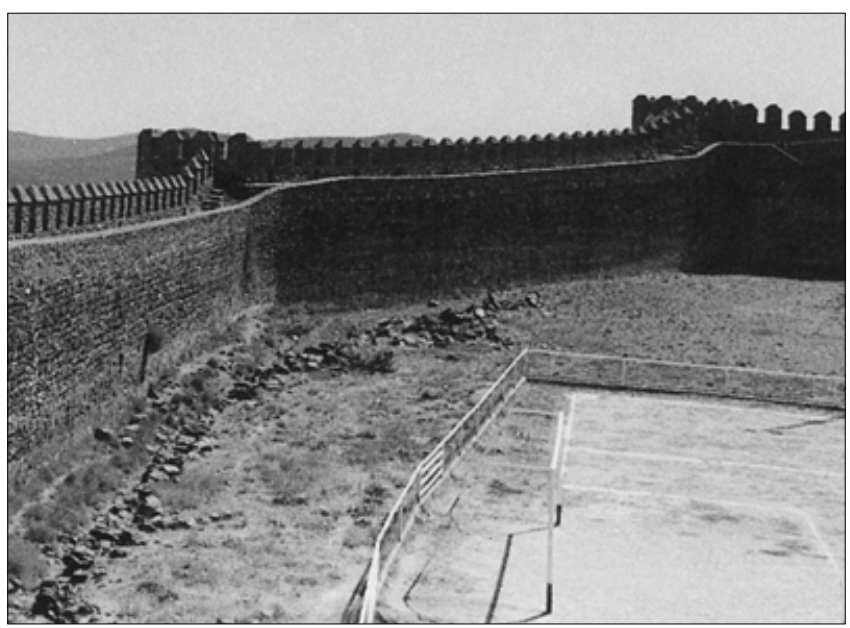

I. Castillo de Cumbres Mayores. Detalle.

2. Murallas de Carmona. Puerta de Sevilla.

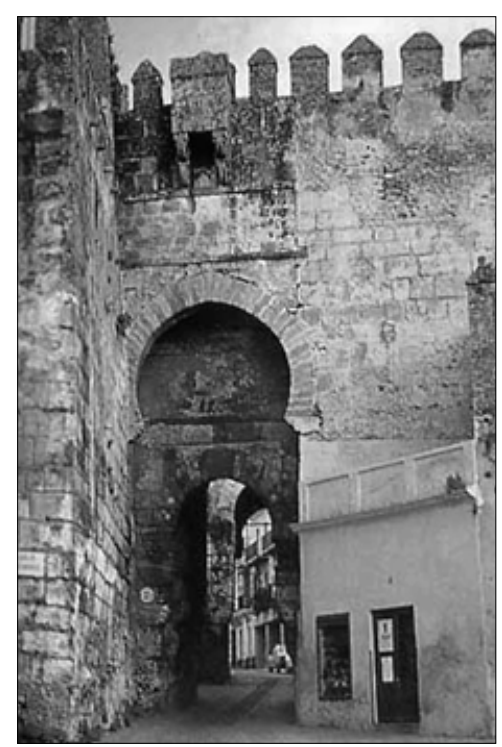

aún hallándose en lugares tradicionalmente marginales para este tipo de actividades.

Son muchas las dificultades planteadas para una recuperación eficiente de este rico patrimonio. En algunos casos, el grado de deterioro es tal que resulta irreversible. En otros, la propiedad de los mismos dificulta una gestión eficaz y su valoración como servicio público. La falta de recursos económicos tampoco debe desdeñarse. No obstante, a pesar de todo ello, en un horizonte cercano, se halla la posibilidad de afrontar unos trabajos que siempre deben tener como referencia el conocimiento profundo de un legado cuyo estudio resulta tan apasionante como complejo. Las fortificaciones medievales de Andalucía Occidental forman un conjunto monumental excepcionalmente rico. Torres, castillos y murallas componen un abundante y variado catálogo, forjado por culturas muy diferentes. Durante la Antigüedad, los tartesios, los iberos y, particularmente, los romanos dejaron una red de infraestructuras y fortificaciones que fue heredada, en primer lugar, por los visigodos, luego, por musulmanes y cristianos. De este modo, nos encontramos con una realidad de compleja caracterización, si cabe, dificultada por la falta de testimonios escritos y el alto grado de deterioro de muchas obras. En este contexto debe interpretarse el análisis de un legado forjado en dos grandes períodos: el de la dominación islámica, que ocupa desde el 7II hasta mediados del siglo XIII, y el de la posterior dominación cristiana, que se extiende desde entonces hasta finales del siglo XV.

\section{Las defensas andalusíes en el valle del Guadalquivir}

La llegada de los musulmanes a la Península, en el año $7 \mathrm{I}$ I, supuso un hito tan importante en el desarrollo de nuestra historia que, puede decirse, que con este hecho se inaugura lo que conocemos como Edad Media, un período abierto en la mayor parte de Europa tras la caída del Imperio Romano.

La ocupación islámica se tradujo en la creación de un dominio conocido como Al-Andalus. Se trataba de un vasto territorio que, a diferencia de lo que ocurría en la Europa cristiana, había retomado el vigor de las ciudades antiguas, dándole un nuevo y personal impulso. La importancia de la vida urbana en el Islam, de este modo, pronto se hizo palpable; especialmente en aquellos lugares que presentaban una situación privilegiada, por su papel económico y estratégico. Este fue el caso del Valle del Guadalquivir, un territorio que, protegido de las tierras del norte y abierto a las cercanas costas africanas, presentaba una fértil vega, explotada eficazmente desde época romana. Fue allí donde se hallaban dos de las ciudades más importantes: Córdoba y Sevilla. La primera, auspiciada por la dinastía Omeya, fue su capital hasta principios del siglo XI. La segunda, tomaría su relevo, para convertirse en la sede de la taifa más poderosa, en el siglo Xl, y en la capital de los almo- 
hades desde mediados del siglo XII, hasta que finalmente, en la segunda mitad de la última centuria, todo el valle quedó en manos cristianas.

Durante este largo espacio de tiempo, la presencia de los musulmanes en el Valle del Guadalquivir permitió el desarrollo de una serie de planes defensivos que han marcado indefectiblemente el curso de la historia en Andalucía. No obstante, su aportación se produjo de un modo gradual y evolutivo, pues cada período dejó su huella en el desarrollo de las construcciones defensivas.

En muchos casos se utilizaron, mantuvieron y transformaron las infraestructuras y construcciones tomadas a los visigodos; las cuales se remontan, en ocasiones, a época prerromana. Tal es el caso del complejo defensivo de la Puerta de Sevilla, en Carmona, estudiado por Alfonso Jiménez. Dicho autor defiende la existencia de una construcción defensiva cartaginesa, luego ampliada por los romanos, quienes hicieron de Carmo uno de los centros urbanos más importantes de la región. Sobre esta base, en el siglo XI, cuando la ciudad se convirtió en un reino de taifa independiente, recibió las primeras obras islámicas, definitivamente cerradas en el período almohade (foto 2).

El aprovechamiento de las fábricas preexistentes resultó especialmente importante al principio, cuando los Omeyas plantearon la organización de un estado aún dotado de medios precarios. En los siglos VIII y IX, una buena parte del sistema de comunicaciones, infraestructuras y fortificaciones hallaban su base en los restos romanos y visigodos, los cuales seguían caracterizando las cercas de las principales ciudades del Valle del Guadalquivir. Poco a poco, sin embargo, las particulares necesidades de un estado centralizado como el cordobés, se tradujeron en la construcción de obras a fundamentis. La erección del Dar alImara, patrocinado por Abd al-Rahman III en Sevilla, en el año 9|3, se concibió como una estructura destinada a preservar los intereses del emirato en una ciudad que se había sublevado contra su autoridad. Tal como había ocurrido en Mérida, en tiempos de Abd al-Rahman II, estos hechos permitieron una revisión del sistema defensivo, que incluía el debilitamiento de las defensas locales y la creación de un alcázar, desde el cual la élite gobernante podía imponer su autoridad. En esta obra realizada con sillares romanos, que nos remite a los recintos fortificados que los Omeyas levantaron en Oriente Próximo, se halla el origen del complejo residencial de los Reales Alcázares.

La creación de nuevas construcciones no hizo sino acentuarse durante el califato, cuando ya se halla perfilado un completo sistema defensivo, destinado a proteger las fronteras del estado $y$, particularmente, los caminos hacia la capital. La fortaleza costera de Tarifa, levantada en el año 960, o la cordobesa de El Vacar, protegiendo el acceso desde Sierra Morena, evidencian el desarrollo de un sistema, cuya culminación se hallaba en la propia Córdoba. Protegida por una estructura muraria de magníica cantería, a soga y doble tizón, hallaba su más elevada expresión en el Alcázar; un conjunto defensivo y residencial que, prácticamente desaparecido, sólo podemos conocer por los testimonios literarios árabes.

Ya entonces era un hecho evidente que el Islam había devuelto a las ciudades andaluzas el vigor que antaño tuvieron, otorgándoles una nueva personalidad. En este contexto, la muralla se convirtió en un elemento clave para la defensa y vertebración del complejo entramado de calles y casas, perfilado en las ciudades andalusíes. En muchos casos, se mantuvieron y adaptaron las cercas romanas, en otros, se construyeron otras nuevas. Pero siempre, el resultado último fue la generación de unos trazados genuinos, cuya honda presencia aún puede experimentarse.

En el siglo Xl, parece perfectamente asimilada una concepción de la ciudad, jerarquizada por principios defensivos. Por una parte, hallamos la muralla con sus torres y puertas, por otra, la alcazaba. Esta era algo más que un simple castillo. Se trataba de un complejo arquitectónico que aglutinaba junto a la función defensiva, la administrativa y la residencial. En ella se alojaba el príncipe o el gobernador, los altos cargos de la administración y la guarnición que los protegía. Instalada en un lugar estratégico, en el extremo de la medina, poseía una cerca propia, con acceso directo al exterior. Podía convertirse en el último reducto ante una amenaza externa, pero también permitía una defensa de la élite gobernante frente a la población. En sí mismo era la más elevada expresión del poder, que separaba un cuerpo de la ciudad, del resto. La alcazaba, traída desde Oriente a la Península, acabaría dominando muchas ciudades andaluzas: Córdoba, Sevilla, Niebla, Carmona, Granada, Almería, Málaga, etc. En el siglo XI, además, entre sus muros se hallaban las sedes de los reinos de taifas que, tras el derrumbamiento del califato, se adueñaron de un territorio fragmentado. Como resultado de ello, muchas de estas construcciones alojaron estancias palatinas que satisfacían las necesidades de las pequeñas cortes surgidas con el nuevo orden. Paradójicamente, el final del califato favoreció la difusión de los primores de la corte cordobesa, hasta lugares donde la sede del poder aparecía dominada por un tono militar y administrativo. Este fue el caso del Alcázar de Sevilla, ampliado por los reyes abadíes; quienes al levantar el mítico Qasr al-Mubaraq, sumaron un palacio al castillo.

Débiles frente a la amenaza cristiana, los reinos de taifas debieron acudir a la ayuda de los almorávides, quienes Ilegaron para quedarse. Al-Andalus había salvado su integridad pero no su independencia. A partir del año 1090 pasó a formar parte de un imperio cuya capital se hallaba en Marrakech. La amenaza cristiana y el sometimiento de los andalusíes debieron preocupar a los nuevos señores, quienes emprendieron un plan defensivo recogido en las fuentes escritas, pero difícilmente delimitable a través de las propias obras. Sabemos de la existencia de obras en Córdoba, Niebla, Jerez y Sevilla. Pero se 


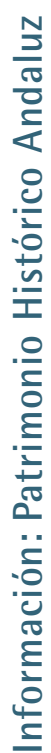

3. Catedral de Sevilla. Maqueta situada en el Retablo Mayor (principios del siglo XVI) desconoce el alcance de las mismas. Esta presencia casi fantasmagórica, hace que se mantengan importantes dudas sobre su participación en proyectos culminados posteriormente por sus sucesores, los almohades. No obstante, observando sus aportaciones en África, podría defenderse la existencia de una cierta continuidad entre un período y el otro.

En todo caso, debemos atribuir a los almohades, la definición de una serie de proyectos entre los que destacan las grandes cercas de Jerez, Niebla, Alcalá de Guadaira y Sevilla. La construcción de esta última debe inscribirse en un vasto programa constructivo, iniciado en I 172. Nuevos palacios en los Alcázares, una nueva mezquita aljama y toda una serie de infraestructuras, entre las cuales destacaron un acueducto, conocido como los Caños de Carmona, un puente de barcas y las atarazanas instaladas en el Arenal. La muralla, desbordando la primitiva cerca emiral, probablemente de origen romano, alcanzaba más de siete kilómetros de longitud. Levantada con un material tan barato y flexible como el tapial, se concibió con trece puertas y ciento sesenta y seis torres de diferente estructura. Su trazado no era regular, sino que se ceñía a la orografía del terreno y a las propias necesidades defensivas. Además, incorporaba soluciones tan notables como la barbacana de la Macarena y la Torre del Oro. Esta última era una torre albarrana, una especie de apéndice que se proyectaba desde los Alcázares, con los que se unía por un muro o coracha, para poder controlar el paso por el río. La gran reforma planteada por los almohades marcó la vida futura de Sevilla, tras su caída en 1248. Hasta el siglo XIX, la ciudad que fuera sede del monopolio americano vivió ceñida por sus muros, tal como muestra la maqueta de la ciudad que se halla en el retablo de su Catedral (foto 3).

Sin duda alguna, de entre todas las soluciones dadas por el Islam a la arquitectura defensiva en la Penín-

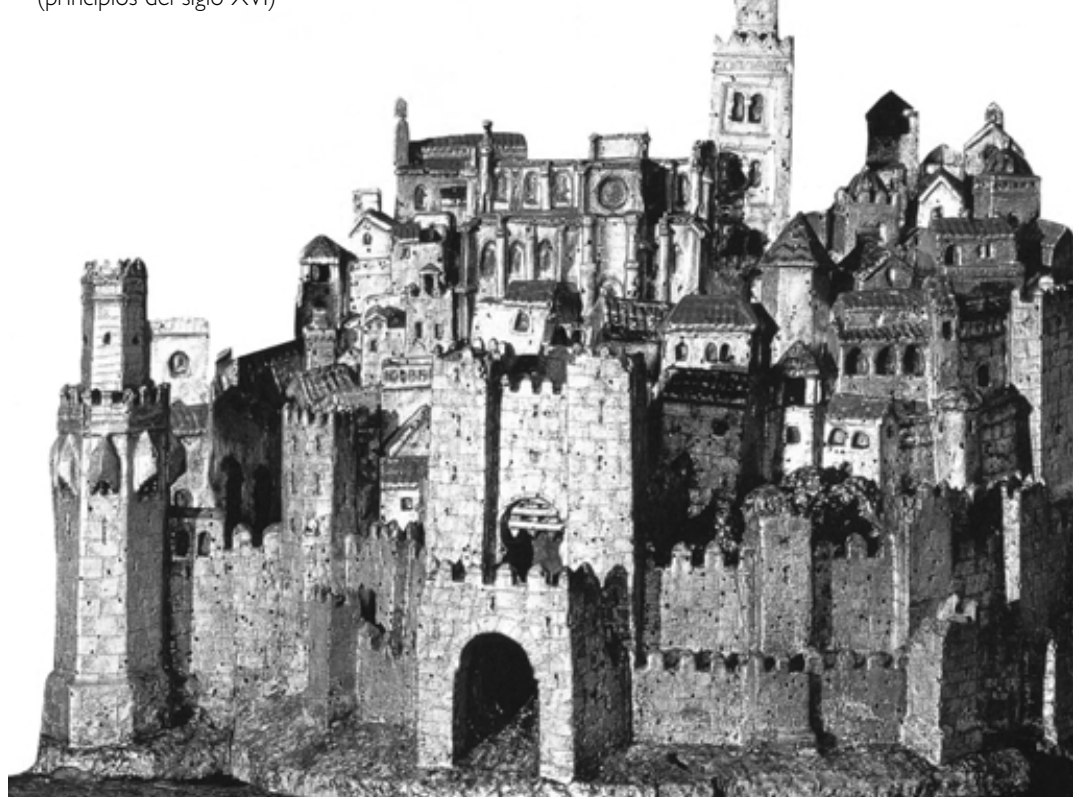

sula, las almohades fueron las más complejas y elaboradas. Su legado fue fundamental para el desarrollo de la arquitectura nazarí. Sin embargo, no encontró un heredero musulmán en Andalucía Occidental pues, a mediados del siglo XIII, el poder almohade se derrumbó, dejando el Valle del Guadalquivir libre a los cristianos.

\section{Las defensas castellanas en los reinos de Córdoba y Sevilla}

Las conquistas cristianas durante el reinado de Fernando III el Santo permitieron la retirada casi total de los musulmanes en el Valle del Guadalquivir. Sin embargo, la coexistencia entre unos y otros aún perduraría largo tiempo, pues el avance castellano se hizo lento hasta tomarse Granada en I492. Esta circunstancia y la presencia amenazante del reino portugués permitieron que durante toda la Baja Edad Media nunca se perdiera ese característico ambiente bélico que destacábamos; lo cual, a su vez, favoreció el mantenimiento y desarrollo de empresas defensivas. Los sólidos muros, las almenas y matacanes dominaban todo tipo de obras; no sólo las fortalezas, sino también los palacios, las casas y los propios conventos e iglesias, tal como puede verse en fundaciones como las de San Antón de Trigueros o San Isidoro en Santiponce.

En primera instancia, el aprovechamiento de las fábricas andalusíes fue sistemático. Se carecía de recursos y tiempo para emprender grandes campañas constructivas en plena guerra y la conquista había ofrecido grandes edificios, cuya reparación era rentable. Puede decirse que el acto de mayor valor arquitectónico practicado por la Corona castellana fue la apropiación física y simbólica de las grandes construcciones oficiales andalusíes, entre las cuales destacaban los castillos y alcazabas.

No obstante, progresivamente, fueron surgiendo los primeros testimonios de una arquitectura que debía responder a las necesidades de los nuevos señores. Dichas obras, por una parte, respondían a los modelos góticos traídos del norte que, desde tiempos de Alfonso X el Sabio, se iban introduciendo lentamente. Por otra, con frecuencia, incorporaban las técnicas y las formas de los conquistados, dando lugar a lo que se conoce como arquitectura mudéjar.

Para el control y pacificación del territorio, se creó un vasto programa defensivo, auspiciado por la Corona y apoyado por la nobleza y las órdenes militares, a quienes se encomendó la primera línea fronteriza. En el siglo XIII, el territorio andaluz se organizó en tres reinos: Jaén, Córdoba y Sevilla. Sus tres capitales se convirtieron en ciudades de realengo, donde la Corona planteó grandes obras. De entre todas ellas, habría que destacar los nuevos palacios levantados en el recinto de los antiguos alcázares. Para proteger a las grandes capitales se diseñó un sistema defensivo formado por fortalezas, en torno a las cuales, 
con frecuencia, surgieron nuevos núcleos de población. En este contexto, Córdoba contó con defensas tan sólidas como el impresionante castillo de Almodóvar del Río, y Sevilla con otras tantas, como las fundaciones islámicas de Alcalá de Guadaira y de Carmona, entonces reformadas. De un modo más directo, frente a la amenaza del reino granadino, se creó todo un cinturón defensivo a lo largo de la frontera, conocida como la Banda Morisca. Partía de las fortalezas jiennenses de Hornos de Segura y Cazorla, pasando por otras cordobesas como las de Espejo y Priego, y sevillanas como las de Estepa y Morón, hasta las gaditanas de Arcos y Medina Sidonia. Este cinturón se cerraba con la protección de las poblaciones cercanas al Estrecho, amenazadas por granadinos y meriníes. Jerez, El Puerto de Santa María, Cádiz, Tarifa y, luego, Algeciras, tras la Batalla de Salado, formaron parte de esa protección, completada con la formación de una flota, cuya base se hallaba en el Puerto de Sevilla, donde se instaló la sede del Almirantazgo. Muchas de las fortalezas mencionadas se convirtieron en la sede de las grandes casas nobiliarias, que obtuvieron de la Corona bienes y privilegios excepcionales en la región.

Si la principal preocupación de la Corona era la defensa del territorio frente a los musulmanes, a Occidente, la presencia del reino portugués, en diferentes momentos, resultó amenazante para los intereses castellanos. Para protegerlos, se creó un programa defensivo en las Sierras del norte de Huelva y Sevilla, lo que se conoce como la Banda Gallega. Allí se acondicionaron castillos de origen árabe como los de Aracena, Aroche y Cortegana; y se levantaron otros nuevos como los de Cumbres Mayores y Santa Olalla, en tiempos de Sancho IV. Mientras, al Sur, las defensas de Ayamonte y de Niebla, mantenidas por los Guzmanes, se erigieron en el baluarte más importante frente a la expansión lusitana (foto 4).

Este programa, que fue completándose entre los siglos XIII y XV, acogió obras de muy diferente condición, cuya evolución era manifiesta. La creciente importancia adquirida por el fuego artillero introdujo algunos cambios notables, tal como se advierte en la construcción de "El Cubete", un fortín artillero instalado a finales del siglo XV en el Alcázar del rey don Pedro en Carmona (foto 5). De igual manera, estos edificios se fueron adaptando a las nuevas condiciones de una sociedad que acogía una aristocracia poderosa y enfrentada, cuyas fortalezas aspiraban a convertirse en el más elevado reflejo de su poder y ostentación.

La ampliación del Castillo de Marchenilla, en Alcalá de Guadaira, el Alcázar de los Guzmanes en Niebla, la fortaleza de Almodóvar del Río, o el Castillo de Belalcázar, en Córdoba, forman parte de un rico repertorio. En este último, particularmente, se advierte un nuevo interés por convertir la fortaleza en una residencia, capaz de proyectar simbólicamente los ideales del señor y de la familia que lo regenta (foto 6).

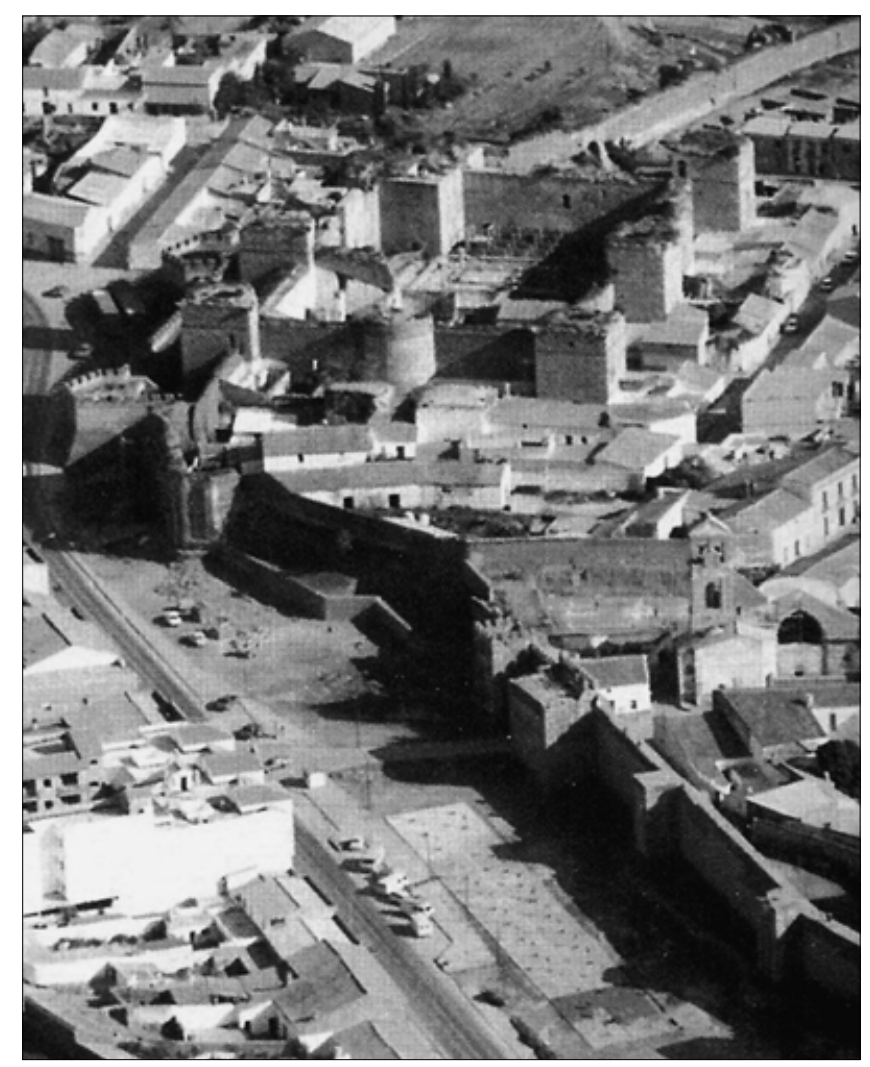

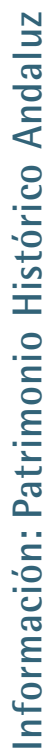

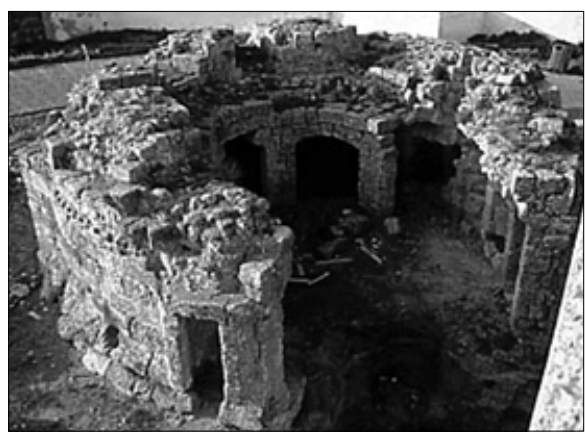

4. Murallas de Niebla. Castillo de los Guzmanes.

5. Alcázar del Rey don Pedro en Carmona. El Cubete.

6. Castillo de Belalcázar.

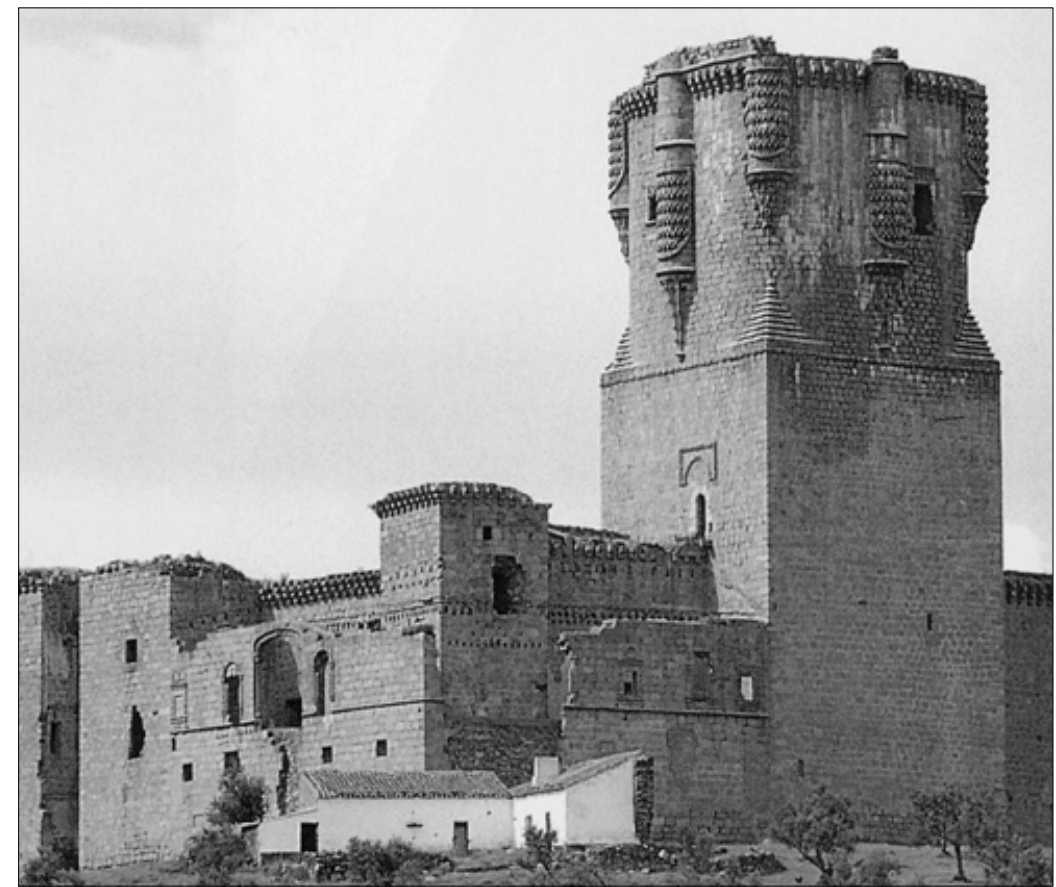


Con unos orígenes que se remontan a la época romana, fue entregada en 1444 a don Gutierre de Sotomayor, maestre de la Orden de Alcántara y conde de Belalcázar. Fue a partir de entonces cuando se levantó un castillo de planta rectangular en el que destaca su imponente torre del homenaje, dispuesta en dos cuerpos. El primero es de planta cuadrada, mientras que el segundo tiende a la forma de un cilindro, con garitones adosados donde se tallaron los escudos con las armas de los señores. En tiempos del duque don Francisco de Sotomayor (I53|-1544), en el costado sur-oriental se levantó un palacio plateresco, del que aún se conservan parte de sus muros. El largo camino recorrido por la fortaleza de Belalcázar, hasta convertirse en una residencia palatina, evidencia los cambios operados en la nobleza castellana; lo cual también se aprecia en el castillo-palacio de Bornos (Cádiz), erigido por la Casa de Medinaceli. La creación de residencias más cómodas y ostentosas, y la exhibición de los atributos nobiliarios son elementos muy característicos de ese período último, protagonizado por el gótico tardío $y$, en buena medida, alimentado por una mitificación de esa cruzada que fue la conquista de Al-Andalus. Sin duda alguna, los ideales caballerescos se exaltaban con mayor brillo cuando ya la guerra tocaba a su fin.

El final de la Guerra de Granada y la reforma del estado planteada por los Reyes Católicos, acabaron con el orden establecido hasta el momento. Sin embargo, ello no supuso la pérdida de la vigencia de los sistemas defensivos medievales. Hubo lugares donde el desplazamiento del centro de la actividad supuso un cierto abandono, como ocurrió en Morón. Esta población situada en la Frontera, fue objeto de los cuidados de los Girón. Pero, en el siglo XVI quedaría relegada a un segundo orden por los señores, que instalaron su residencia en la cercana Osuna, nuevo centro de sus actividades constructivas.

Sin embargo, la Corona y las casas nobiliarias siguieron haciendo uso de estos baluartes durante varios siglos y una buena parte de los planes generales de defensa, permanecieron vigentes. La frontera portuguesa siguió siendo conflictiva hasta el siglo XVIII. Durante largos períodos, como ocurrió con la separación de Portugal y la guerra de Sucesión, las tierras onubenses se vieron una y otra vez asoladas por la miseria y la violencia que trae toda guerra. Ello permitió que los planes defensivos siguieran actualizándose hasta la época de Carlos III. De igual manera, la defensa del litoral siguió siendo necesaria. Los actos de piratería mantenidos por berberiscos e ingleses exigieron una total reforma de los programas medievales, cuya capacidad había quedado sobradamente superada. Los muros se hacían más recios, más gruesos y cerrados. Los puestos de artillería cobraban mayor importancia, a la vez que surgían trazados angulosos. Sin embargo, aún durante largo tiempo, las altivas torres con blasones y matacanes sobrevivirían a la hostilidad de la naturaleza y del hombre, como recuerdo de un tiempo que aún perdura.

\section{Bibliografía}

CASQUETE DE PRADO SACRERA, NURIA: Los castillos de la Sierra Norte de Sevilla en la Baja Edad Media. Sevilla: Diputación Provincial, 1993.

COLLANTES DE TERÁN Y DELORME, FRANCISCO: Los castillos del Reino de Sevilla, Archivo Hispalense, nº 58-59 (1967)

ESLAVA GALÁN, J.: Origen y función de la alcazaba, Koiné, n² (I986), pp. 26-32.

FERNÁNDEZ, JOSÉ JUAN; RAVÉ, JUAN LUÍS; y RESPALDIZA, José: Los castillos a través de la historia. Jornadas europeas de Patrimonio Histórico (1997). Sevilla: Junta de Andalucía, 1997.

GARCÍA FERNÁNDEZ, M. (Ed.): La Banda Morisca durante los siglos XIII, XIV y XV. Ed. M. García Fernández. Morón de la Frontera, 1996

JIMÉNEZ MARTÍN, ALFONSO: La puerta de Sevilla en Carmona. Málaga, 1989.
MORALES MARTÍNEZ, ALFREDO: Arquitectura medieval en la Sierra de Aracena. Sevilla: Diputación Provincial, 1976.

PAREJA LÓPEZ, ENRIQUE: El arte en el Sur de Al-Andalus. Historia del arte en Andalucía, vol. II. Sevilla: Editorial Gever, 1988.

PAREJA LÓPEZ, ENRIQUE. El arte de la Reconquista cristiana. Historia del arte en Andalucía, vol. III. Sevilla: Editorial Gever, 1998.

PAVÓN MALDONADO, BASILIO: Tratado de arquitectura hispano-musulmana. II Ciudades y fortalezas. Madrid: C.S.I.C., 1999

VALOR PIECHOTTA, MAGDALENA: La arquitectura militar y palatina en la Sevilla musulmana. Sevilla: Diputación Provincial, 1991.

VALOR PIECHOTTA, MAGDALENA: Las fortificaciones medievales en el reino de Sevilla. Arqueología en el entorno del BajoGuadiana. Ed. J. Campos et alii. Huelva, 1994, pp. 645-655. 